\title{
How Communication Disharmonies between Patients and Nurses Can Affect Patients-A Qualitative Study of Illness Experienced from the Patients View
}

\author{
Marianne K. Thygesen ${ }^{1,2^{*}}$, Birthe D. Pedersen ${ }^{1}$ \\ ${ }^{1}$ Institute of Clinical Research, Faculty of Health Sciences, University of Southern Denmark, Odense, Denmark \\ ${ }^{2}$ Surgery Department A, Odense University Hospital, Odense, Denmark \\ Email: *marianne.thygesen@rsyd.dk
}

How to cite this paper: Thygesen, M. K., \& Pedersen, B. D. (2017). How Communication Disharmonies between Patients and Nurses Can Affect Patients-A Qualitative Study of Illness Experienced from the Patients View. Psychology, 8, 526-537.

https://doi.org/10.4236/psych.2017.84033

Received: December 14, 2016

Accepted: March 11, 2017

Published: March 14, 2017

Copyright $\odot 2017$ by authors and Scientific Research Publishing Inc. This work is licensed under the Creative Commons Attribution International License (CC BY 4.0).

http://creativecommons.org/licenses/by/4.0/

\begin{abstract}
Patient-provider interaction is important for cancer patients' wellbeing and further coping and it might be beneficial to further investigate this in the fast track trajectories. Cancer patients experience themselves as liminal and we aimed to investigate how patients experience healthcare professionals' attitude with regard to the patients' own illness experience. Diaries, observation notes, and an elicitation technique supported in the semi-structured interview situations with eight female patients few days after discharge after gynecological cancer surgery were used. Data were transcribed verbatim and analyzed using a Ricoeur inspired technique, which started open-minded. Situations with harmony between patients' experience of their health state and nurses' signals in this regard were more peaceful and energizing for the patients than situations with disharmony, which gave limbo experiences and drained of energy. The Broaden and Build theory and the Sense of Coherence theory might support our findings. True presence of the nurse is important in order to meet the patient where she is and communicate from there. More evidence based suggestions for future clinical foci are given. Female cancer patients can be vulnerable to healthcare professionals' small signals regarding the patients' state of health, and harmony or disharmony between these signals and patients' own experiences means a difference to their psychological wellbeing. It might also mean a difference to early mobilization.
\end{abstract}

\section{Keywords}

Health State, Healthcare Professional, Female Cancer, Patient-Nurse Interaction, Fast Track Trajectory, Liminality, Limbo, Early Mobilization 


\section{Introduction}

This paper deals with cancer patients' experiences of their healthcare received in the in-hospital period after surgery. The study is a part of a larger study, which investigated cancer patients' experiences of received healthcare, and from which patients' experiences with a pre-hospital offer of a nurse navigator were reported (Thygesen et al., 2011a; Thygesen et al., 2012). Patient-provider interaction is important for cancer patients' wellbeing and further coping (Arora, 2003; Seetharamu et al., 2007; Hillen et al., 2011). A trusting relationship between the patient and the provider is in a review from 2011 reported to facilitate "communication and medical decision making, decrease of patient fear, and better treatment adherence" (Hillen et al., 2011), so patient's trust in the healthcare provider is one of the desired outcomes in the patient-provider interaction. Others might be decrease of anxiety or increase of quality of life. This might all be reached by healthcare professionals being honest, reassuring and acknowledging; and who minimize the potential for experience of shame, humiliation, abuse or misuse during the interaction as well as showing technical competences (Seetharamu et al., 2007; Hillen et al., 2011). Moreover, it is important to show verbal and nonverbal support including giving understandable information, and engaging patients in decision making (Arora, 2003). This mirrors those attitudes of healthcare professionals which are found to give high satisfaction among gynecological patients (Thygesen et al., 2015). However, a review has called for more research on the relationship between the professionals' behavior and the outcome for the cancer patient (Arora, 2003). The significance of healthcare professionals' behavior on the patients' psychological outcome is grounded in patients' experiences of the interaction, which will be interpreted by personal filters influenced by present and earlier experiences (Thygesen et al., 2012; Løgstrup, 2008; Hillen et al., 2014). This makes care challenging, as what professionals do and intend to signal is not always experienced the intended way by the patients (Thygesen et al., 2011b; Silverman et al., 2005).

From the patient's view, to get cancer means to become ill, but to complete treatment does not necessarily mean to become healthy, regardless of whether a relapse is avoided or not (Blows et al., 2012). Once cancer has entered the patient's life (s)he enters and often remains in an unpleasant experience of liminality as a health state between very sick and very healthy (Blows et al., 2012; Holmberg, 2014). The health condition becomes a vulnerable issue, and it might be valuable to know more about the patient-provider interaction in this regard. The most emotionally stressed cancer patients might be those in gynecological cancer trajectories (Larouche \& Edgar, 2004), which is why we focus on these.

\section{Methods}

We aimed to investigate how patients experience healthcare professional attitude with regard to the patients' own illness experience, and used data collected in 2008 in conjunction with a Danish university hospital, which served more than two million people. In order to grasp the patients' experiences, a qualitative method was chosen. The data was collected at the same time as data for another 
part of the study: Only data and results regarding healthcare professional support before admission to hospital have earlier been reported (Thygesen et al., 2011a; Thygesen et al., 2012). Data and results with regard to patients' experiences of healthcare professional help in the in-hospital period have not previously been reported and is used for this paper. The study took a phenomenological-hermeneutical approach and was inspired by Ricoeur's theory of narrative and interpretation (Ricoeur, 1979; Pedersen, 1999; Lindseth \& Norberg, 2004; Dreyer \& Pedersen, 2009).

This study was given CVR nr. 11-88-37-29 at the Danish Data Protection Agency. The Ethics Committee of the Region of Southern Denmark required no ethical approval of this study and waived a request. The study adheres to the Declaration of Helsinki (Williams, 2008) and Ethical guidelines for Nursing Research in the Nordic Countries (NoName, 2003). The participants received written and oral information about the study, they signed informed consent before enrolment in the study, and they were all guaranteed full anonymity when results are reported.

\subsection{Participants}

For the whole study, participants were all referred to a gynecological outpatient clinic with suspicion of cancer and were consecutively included at time of referral, if they could speak and understand Danish. No exclusions were made in order to optimize diversity in the sample. In the data collection period, a new elicitation technique was conducted and used in the last part of the interviews (Thygesen et al., 2011b). For this paper, we used a convenience sample of data from those participants who in the interview had participated in the elicitation technique. At the time for interview, they were all newly discharged after intended curative surgery following cancer suspicion but had not all a final diagnosis. Eight women between 36 years and 78 years of age participated (Table 1).

\subsection{Data Collection}

The data for this study were narratives obtained through semi-structured interviews (Kvale \& Brinkmann, 2009). All interviews were conducted face to face by the first author. All participants had met this researcher in the outpatient clinic and they knew the researcher was from the university and was interested in how they experienced their disease trajectory. The interviews for the whole study took place where the single patient preferred to have this talk, which for a few patients were in a private setting at an outpatient clinic, and for the rest were in patients' private homes. These interviews were supported by the participants' filled out semi-structured diaries and first authors field notes from the single participants

Table 1. Some similarities and differences between the eight participants.

\begin{tabular}{cccccc}
\hline Age (mean) & Married & $\begin{array}{c}\text { Live at the } \\
\text { country site }\end{array}$ & $\begin{array}{c}\text { Ovaries, corpus } \\
\text { or cervix surgery }\end{array}$ & $\begin{array}{c}\text { Corpus and } \\
\text { cervix surgery }\end{array}$ & $\begin{array}{c}\text { Known cancer } \\
\text { diagnosis at } \\
\text { discharge }\end{array}$ \\
\hline $36-78(61.3)$ & 8 & 4 & 6 & 2 & 4 \\
\hline
\end{tabular}


visit to the outpatient clinic, both used solely to support the patients' memory and increase the interviewers possibility of asking meaningful questions. Moreover, a visual elicitation technique was used, conducted in the study with the aim of supporting patients' memory regarding events in the healthcare system and the evoked emotions (Thygesen et al., 2011a). In the interviews, open questions were used such as "How have you experienced your course of disease?", "How could you use the available healthcare resources?", "Were your needs met?" and if not: "Will you elaborate?" Due to the explorative design, the patients had the opportunity to bring up the issues that were most important to them, including events perceived as good/bad and they could freely express their attitude and tell their own story (Pedersen, 1999; Ricoeur, 1984; Ricoeur, 1985). After this first part, the elicitation technique was added; a grid on a piece of paper with preprint of a standardized trajectory of contacts with the healthcare system on the $\mathrm{x}$-axis. The events on the $\mathrm{x}$-axis were then collaboratively annotated. Thereafter, the participant was introduced to the $y$-axis as a self-elected emotion going from $0 \%$ to $100 \%$ and she was asked to choose a salient emotion and make a graph on the paper, eventually rate each event with regard to the emotion and make a graph from dot to dot. In this part of the interview, while making these emotional dots and the graph(s), most participants talked by themselves and in this way the elicitation technique took over the questions regarding the relation between experienced emotions and events in the healthcare system. All participants enriched the interview data with new information about a known event, with more events, and/or participants gave a better connection between time, concrete events and emotions (Thygesen et al., 2011b). The grid was verbalized, so the interviews could stand alone and were the only part for further analysis and interpretation. The interviews lasted from one to one and a half hours, were audio-recorded, and transcribed verbatim.

\subsection{Analysis}

The analysis and interpretation was inspired by Ricoeur (Ricoeur, 1979; Pedersen, 1999), with a naïve reading covering the first interpretation of what the text opens for between the text and the reader, and thereafter, a structural analysis going from what is said to what is talked about and ending in themes. This was followed by a comprehensive understanding including discussion with existing literature (Ricoeur, 1979; Pedersen, 1999; Lindseth \& Norberg, 2004; Dreyer \& Pedersen, 2009).

In the naïve reading, the text was read several times from a phenomenological perspective. The interpreter attempted to be open-minded and allowed the text to speak to her; the meaning as a whole was understood and the first conjunctures were made (Pedersen, 1999; Lindseth \& Norberg, 2004). In the structural analysis, the units of meaning were described (what was said). The units of meaning were reflected on in relation to the naïve reading and units of significance (what the text was talking about) were formulated. From this, the themes were formulated (ibid.). The meaning of the patients' lived experience was identified in these themes. The intention was to be as objective as possible during the 
structural analysis (ibid.). The analysis was a dialectical process that moved back and forth between understanding and explanation (ibid.).

\section{Results}

The naïve reading and structural analysis pointed to experiences between sick and healthy as important; the experience of signals from the professionals in relation to patients' own experienced health state. Two opposite themes was found; 1) Disharmony as draining of energy and 2) Harmony as giving energy. A central part of the structural analysis is illustrated in Table 2.

In the analysis and interpretation we found, that all patients placed themselves between very sick and very healthy. Table 2 presents that a situation with disharmony between a patient's experience of own health state and of healthcare professional signals regarding the patient's health state was followed by placing oneself closer to the ill end of a continuum between sick and healthy. On the

Table 2. The central part of the structural analysis.

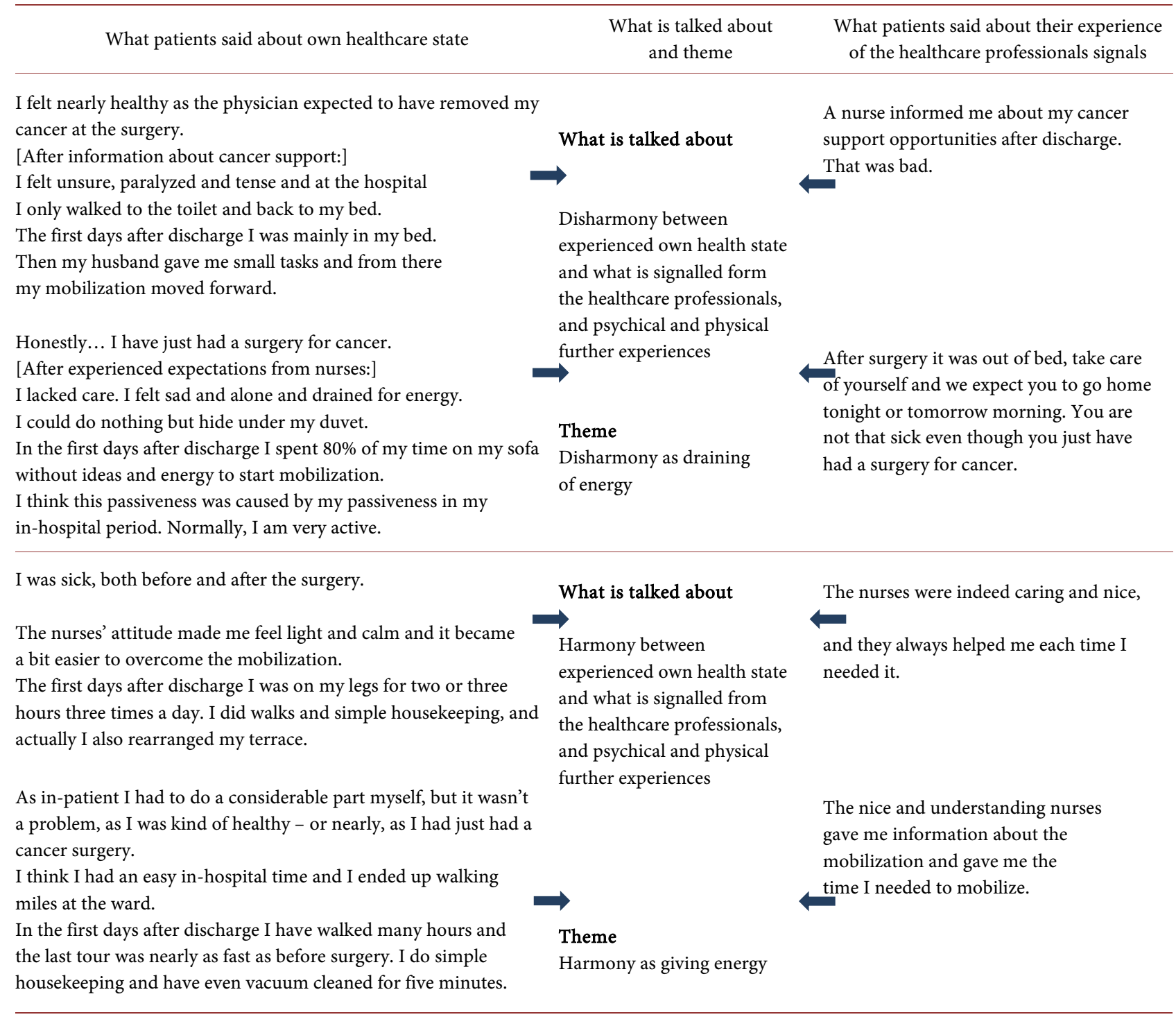


contrary, harmony between such experiences was followed by quick steps to the healthy end of the same continuum. To support the further elaboration figuratively, this continuum is the vertical line in a health cross. The horizontal line reflects the patient's interpretation of the professional's attitude regarding patient's health state (Figure 1). We will further elaborate on the results and use the health cross in Figure 1.

\subsection{Disharmony as Draining of Energy}

Disharmony could be experienced at any time at hospitalization. If such situations is viewed in the light of a health cross (Figure 1), patients could feel rather healthy, but felt treated as sick or reverse, and in both situations, the clear diversity between these experiences confused the patients. It made them "lack care", time stood still, they felt lack of control, and "sad and alone". They met nurses trying to help them follow the mobilization regime at the hospital, but felt wrong and "drained of energy". After discharge, they experienced staying in this mode for days. In such a situation, a relative could be helpful by giving small manageable tasks, relevant for the daily life, e.g. to prepare coffee for a cozy moment with the relative after his workday.

\subsection{Harmony as Generating Energy}

Harmony between healthcare professionals' signals and own experienced state of health was also expressed. Such experiences were rarely mentioned without an invitation to elaborate on a specific care event, either earlier mentioned or mapped when using the visual elicitation technique. However, when expressed, it followed a pattern: patients felt relieved about an atmosphere marked by supporting, knowledgeable and attentive healthcare professionals exuding seriousness. Such situations made a (part of a) course of disease more easy and patients described more physical activity, i.e. the patients were "walking miles" in the ward and/or had redecorated an atrium few days after discharge.

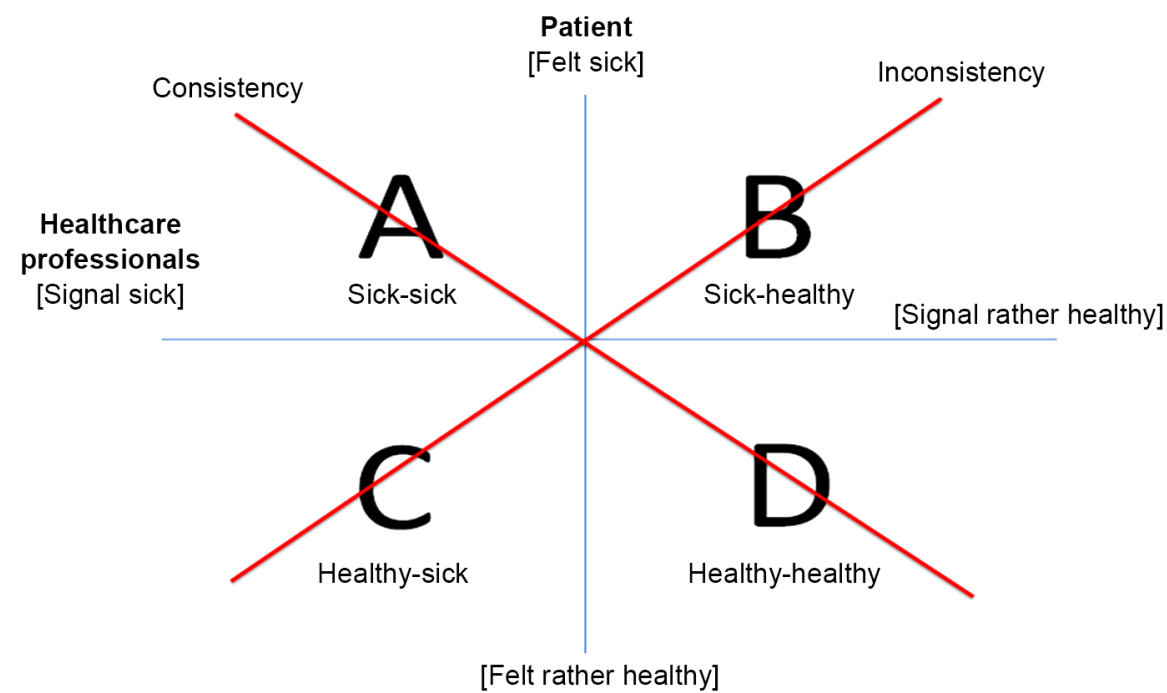

Figure 1. Health cross of experiences and interpretations regarding sick and healthy. 


\section{Discussion}

The patients experienced their own state of health between sick and healthy. This must not puzzle anyone, as patients were interviewed about their experiences in the acute phase with in-hospitalization and surgery for cancer and a following discharge. Moreover, some of them had a cancer diagnosis and the others were still waiting for a diagnosis. Such a state between two culturally accepted concepts (here sick and healthy) can be labeled as a liminal state, which cancer patients are described to enter and stay in for a longer period (Blows et al., 2012), and eventually later transform from it into a new normality (Rasmussen \& Elverdam, 2008).

Patients described experiences of disharmony between own and healthcare professional signals of the patients' health state, followed by uncertainty and decrease of energy. Other patients who felt harmony between own experiences and healthcare professional signals, felt relieved, and found strength to follow the mobilization regime and even increase mobilization after discharge. In this way our findings might support more theories in human behavior: 1) The Broadenand-Build theory from positive psychology, which suggests that experiences of positive emotions make positive influence on personal resources (Fredrickson, 2001). In our example, the patient's positive emotion was created by an experience of intercommunicative harmony caused by a healthcare professional's attitude of recognition and respect. Experiences of such attitudes are important for gynecological patients in order to be very satisfied with the received healthcare (Thygesen et al., 2015). Moreover, such an attitude contributes to a trusting relationship contrary to intercommunicative disharmony, which will contribute to guarded trust or even distrust (Løgstrup, 2008). In our example, it seemed that the positive emotion might have supported creation of increased energy and initiative. 2) The Sense of Coherence theory from sociology, which emphasizes the importance of experienced overview, as one element together with meaningfulness of tasks, and trust in the capability to manage the upcoming challenges, in order to achieve a strong sense of coherence and simply manage better throughout life (Antonovsky, 1987). In our example, a nurse who contributed to a patient's experience of harmony confirmed the patient's judgement of the situation and thus supported the patients trust in ability to create an overview in the hospital environment. The more solid overview might contribute to the patient's more easily being able to take care of themselves. Both the Broaden-and-Build theory and the Sense of Coherence theory emphasize that an increased positive emotional complex supports the competence of action (Fredrickson, 2001; Antonovsky, 1987). We found a possible subsequent mobilization effect after patients' experienced harmony or disharmony between patients' interpretation of healthcare professional attitude and own experienced health state, but our data is not exhaustive in this regard. Early mobilization is regarded important (Bakhru et al., 2015) and is a common part of early recovery pathways after surgery (de Groot et al., 2016; Day et al., 2015). What affects early postoperative mobilization is multifactorial, which need further investigation, and our input might go 
some way to explain why tests of early mobilization programs give mixed results (Castelino et al., 2016).

Moreover, the patients' descriptions of disharmony lead to thoughts of limbo experiences, where earlier events are regarded irrelevant, the time is set on hold, and possible changes seems out of ones' influence (Hazan, 1980). Such experiences are described as extremely unpleasant (Hazan, 1980), which further match our result.

In the transition back to the GP there are research related beliefs, that cancer survivors will improve their standpoint, if they get healthcare professional signals of no expectation of cancer after terminated treatment (i.e. no control appointments at the hospitals) (Mathiesen, 2014). But not all patients are alike. Our research points to the importance of identifying how the single patient's experiences her health state, and communicates from there. This requires "true presence" (Melnechenko, 2003). This means that the nurse, as far as possible, "enters into the world of the other, in order to see that world from the other's perspective" (Melnechenko, 2003: p. 19). It is not only listening-it requires openness to, and non-judgment of, the other in an interrelationship that grasp the changing reality of the other (Melnechenko, 2003). Healthcare professional communication skills are central in all care activities and there are techniques aimed to reduce the clash experiences like those experienced by our participants, for instance to give warnings before the real message, if it is intended to change the patients' idea of own health state (Silverman et al., 2005). Moreover, cancer patients' emotional wellbeing increases when rehabilitation with physical activity and cultivation of new social relations starts under treatment (Adamsen et al., 2009). Such an approach might be fruitful to add to a withdrawal of healthcare professional controls post treatment, as increased social relations might diminish the experience of limbo at the time of terminated treatment.

\section{Limitations}

The interviews used for this paper were collected in 2008. However, the participants' experiences regarding in-hospital care have never been used, and we found the data absolutely suitable; the interviews had a focus on patients' experiences with healthcare professional support, help and attitude, and the patients' self-reported reactions in this regard, and the data were extensive because of the use of the elicitation technique. This technique supported participants' memory and urged them to deepen their narratives by specifying connections between healthcare professional attitude and own experiences, and by adding more words on their thoughts and experiences. Moreover, even though the analysis was performed on all the selected interviews as one big text, the results are reflected in each of the eight interviews. In this way a kind of data saturation might have been reached (Kvale \& Brinkmann, 2009). Our participants were not asked to give feedback on our findings, which is argued to enhance validity to the interpretation of data (Popay et al., 1998). In a Ricoeur inspired analysis and interpretation, a special focus for validation is that the structural analysis must support the (adjusted) naïve reading (Lindseth \& Norberg, 2004). Moreover, an 
analytical point is, that the interpretation does not aim to reestablish the original situation by a focus of the participants' intentions with what was said, but instead to unfold another (newly discovered) possible way to be in the world (Ricoeur, 1979). For instance, our participants talked about their experiences at hospital and at home without a special focus on talking about harmony or disharmony in the communication with healthcare professionals. They might have had multiple agendas, but one main agenda was to tell about their experiences as simply as possible. So, after analyses and interpretations that start open-minded, it might be difficult-and even not correct-to search for participants' acceptance of an interpreted result as reflecting what was originally meant by the narrator. We only included adult middle aged women between 36 and 78 and it might be, that differences in sex as well as differences between adolescents, young adults and middle aged are evident with regard to experiences of own sickness, vulnerability and ways to cope. The results from this study cannot be generalized but is rather transferrable to similar settings.

\section{Conclusion}

Female cancer patients' experience of harmony between own experiences and nurses' signals regarding the patients' health state can be important for patients' wellbeing. A reverse situation with disharmony in this regard can give patients a limbo like experience and, moreover, this might affect the early mobilization in a negative direction. This is important knowledge for nurses when they plan and do their part of the communication with female cancer patients.

\section{Acknowledgements}

We gratefully thank the participants who so generously supported this study, and we thank noncommercial funds at Odense University Hospital and University of Southern Denmark for providing financial support, which had no involvement in neither the research nor the writing and publication. Moreover, we thank the professors Ole Mogensen, Lis Wagner and Jacob Kragstrup who were supervisors at the time of data collection.

\section{Authors' Contributions}

Both authors have contributed to the study idea and the study design. MKT created the elicitation technique, carried out the data collection and the analysis. She and BDP discussed interim results in the process of the analysis. MKT made the first draft of the manuscript with input from BDP, both authors revised it critically and gave approval of the final version to be published.

\section{Competing Interests}

The authors declare that they have no competing interests.

\section{References}

Adamsen, L., Quist, M., Andersen, C., Moller, T., Herrstedt, J., Kronborg, D. et al. (2009). 
Effect of a Multimodal High Intensity Exercise Intervention in Cancer Patients Undergoing Chemotherapy: Randomised Controlled Trial. British Medical Journal, 339, b3410. https://doi.org/10.1136/bmj.b3410

Antonovsky, A. (1987). Unravelling the Mystery of Health How People Manage Stress and Stay Well. San Francisco, CA: Jossey-Bass Publishers.

Arora, N. K. (2003). Interacting with Cancer Patients: The Significance of Physicians' Communication Behavior. Social Science of Medicine, 57, 791-806. https://doi.org/10.1016/S0277-9536(02)00449-5

Bakhru, R. N., Wiebe, D. J., McWilliams, D. J., Spuhler, V. J., \& Schweickert, W. D. (2015). An Environmental Scan for Early Mobilization Practices in U.S. ICUs. Critical Care Medicine, 43, 2360-2369. https://doi.org/10.1097/CCM.0000000000001262

Blows, E., Bird, L., Seymour, J., \& Cox, K. (2012). Liminality as a Framework for Understanding the Experience of Cancer Survivorship: A Literature Review. Journal of Advanced Nursing, 68, 2155-2164.

https://doi.org/10.1111/j.1365-2648.2012.05995.x

Castelino, T., Fiore, J. F. J., Niculiseanu, P., Landry, T., Augustin, B., \& Feldman, L. S. (2016). The Effect of Early Mobilization Protocols on Postoperative Outcomes Following Abdominal and Thoracic Surgery: A Systematic Review. Surgery, 15, 991-1003. https://doi.org/10.1016/j.surg.2015.11.029

Day, R. W., Fielder, S., Calhoun, J., Kehlet, H., Gottumukkala, V., \& Aloia, T. A. (2015). Incomplete Reporting of Enhanced Recovery Elements and Its Impact on Achieving Quality Improvement. The British Journal of Surgery, 102, 1594-1602. https://doi.org/10.1002/bjs.9918

De Groot, J. J., Ament, S. M., Maessen, J. M., Dejong, C. H., Kleijnen, J. M., \& Slangen, B. F. (2016). Enhanced Recovery Pathways in Abdominal Gynecologic Surgery: A Systematic Review and Meta-Analysis. Acta Obstetricia et Gynecologica Scandinavica, 95, 382-395. https://doi.org/10.1111/aogs.12831

Dreyer, P. S., \& Pedersen, B. D. (2009). Distanciation in Ricoeur's Theory of Interpretation: Narrations in a Study of Life Experiences of Living with Chronic Illness and Home Mechanical Ventilation. Nursing Inquiry, 16, 64-73. https://doi.org/10.1111/j.1440-1800.2009.00433.x

Fredrickson, B. L. (2001). The Role of Positive Emotions in Positive Psychology. The Broaden-and-Build Theory of Positive Emotions. The American Psychologist, 56, 218 226. https://doi.org/10.1037/0003-066X.56.3.218

Hazan, H. (1980). Constructing the Life Course (2nd ed.). New York, NY: Ravi Mehra.

Hillen, M. A., de Haes, H. C., \& Smets, E. M. (2011). Cancer Patients' Trust in Their Physician-A Review. Psycho-Oncology, 20, 227-241. https://doi.org/10.1002/pon.1745

Hillen, M. A., de Haes, H. C., Stalpers, L. J., Klinkenbijl, J. H., Eddes, E. H., Verdam, M. G., \& Smets, E. M. (2014). How Attachment Style and Locus of Control Influence Patients' Trust in Their Oncologist. Journal of Psychosomatic Research, 76, 221-226. https://doi.org/10.1016/j.jpsychores.2013.11.014

Holmberg, C. (2014). No One Sees the Fear: Becoming Diseased before Becoming IllBeing Diagnosed with Breast Cancer. Cancer Nursing, 37, 175-183. https://doi.org/10.1097/NCC.0b013e318281395e

Kvale, S., \& Brinkmann, S. (2009). Interviews_Learning the Craft of Qualitative Research Interviewing. London: SAGE Publications Inc.

Larouche, S., \& Edgar, L. (2004). The Measure of Distress. A Practical Thermometer for Outpatient Screening. Oncology Exchange, 3, 34-39. 
http://www.capo.ca/pdf/Larouche\&Edgar_2004.pdf

Lindseth, A., \& Norberg, A. (2004). A Phenomenological Hermeneutical Method for Researching Lived Experience. Scandinavian Journal of Caring Sciences, 18, 145-153. https://doi.org/10.1111/j.1471-6712.2004.00258.x

Løgstrup, K. E. (2008). Den kendsgerneing, hvoraf den tavse fordring udspringer [The Fact from Where the Tacit Demand Originate]. In Den etiske fordring [The Ethical Demand] (pp. 17-39). Copenhagen: Gyldendal.

Mathiesen, M. M. (2014). Follow-Up of Endometrial Cancer Patients (OPAL). Odense: Odense University Hospital. https://clinicaltrials.gov/ct2/show/NCT01853865

Melnechenko, K. L. (2003). To Make a Difference: Nursing Presence. Nursing Forum, 38, 18-24. https://doi.org/10.1111/j.1744-6198.2003.tb01207.x

NoName (2003). Nurses Collaboration in the Nordic Countries. Ethical Guidelines for Nursing Research in the Nordic Countries. Nordic Journal of Nursing Research, \& Clinical Studies/Vaard i Norden, 23, 1-5.

Pedersen, B. D. (1999). Sygeplejepraksis, Sprog, \& Erkendelse [Nursing Practice, Language, \& Cognition]. Aarhus: Fællestrykkeriet for Sundhedsvidenskab og Humaniora.

Popay, J., Rogers, A., \& Williams, G. (1998). Rationale and Standards for the Systematic Review of Qualitative Literature in Health Services Research. Qualitative Health Research, 8, 341-351. https://doi.org/10.1177/104973239800800305

Ricoeur, P. (1979). Interpretation Theory. Fort Worth, TX: The Texas Christian University Press.

Ricoeur, P. (1984). Time and Narrative. In Narrative Time (Vol. 3, Part 4). London: University of Chicago Press.

Ricoeur, P. (1985). Time and Narrative. In The Circle of Narrative and Temporality(Vol. 1, Part 1). London: University of Chicago Press.

Rasmussen, D. M., \& Elverdam, B. (2008). The Meaning of Work and Working Life after Cancer: An Interview Study. Psychooncology, 17, 1232-1238.

https://doi.org/10.1002/pon.1354

Seetharamu, N., Iqbal, U., \& Weiner, J. S. (2007). Determinants of Trust in the PatientOncologist Relationship. Palliative Supportive Care, 5, 405-409.

https://doi.org/10.1017/S1478951507000600

Silverman, J., Kurtz, S., \& Draper, J. (2005). Skills for Communicating with Patients (2nd ed.). San Francisco, CA: Radcliffe Publishing.

Thygesen, M. K., Pedersen, B. D., Kragstrup, J., Wagner, L., \& Mogensen, O. (2011a). Utilizing a New Graphical Elicitation Technique to Collect Emotional Narratives Describing Disease Trajectories. The Qualitative Report, 16, 596-608.

http://nsuworks.nova.edu/cgi/viewcontent.cgi?article=1076\&context=tqr

Thygesen, M. K., Pedersen, B. D., Kragstrup, J., Wagner, L., \& Mogensen, O. (2011b). Benefits and Challenges Perceived by Patients with Cancer When Offered a Nurse Navigator. International Journal of Integrated Care, 11, e130.

https://doi.org/10.5334/ijic.629

Thygesen, M. K., Pedersen, B. D., Kragstrup, J., Wagner, L., \& Mogensen, O. (2012). Gynecological Cancer Patients' Differentiated Use of Help from a Nurse Navigator: A Qualitative Study. BMC Health Service Research, 12, 168.

https://doi.org/10.1186/1472-6963-12-168

Thygesen, M. K., Fuglsang, M., \& Miiller, M. M. (2015). Factors Affecting Patients' Ratings of Healthcare Satisfaction. Danish Medical Journal, 62, A5150.

http://www.danmedj.dk/portal/page/portal/danmedj.dk/dmj_forside/PAST_ISSUE/201 
Williams, J. R. (2008). The Declaration of Helsinki and Public Health. Bulletin of the World Health Organization, 86, 650-652.

https://doi.org/10.2471/BLT.08.050955

Submit or recommend next manuscript to SCIRP and we will provide best service for you:

Accepting pre-submission inquiries through Email, Facebook, LinkedIn, Twitter, etc. A wide selection of journals (inclusive of 9 subjects, more than 200 journals) Providing 24-hour high-quality service User-friendly online submission system Fair and swift peer-review system Efficient typesetting and proofreading procedure Display of the result of downloads and visits, as well as the number of cited articles Maximum dissemination of your research work

Submit your manuscript at: http://papersubmission.scirp.org/ Or contact psych@scirp.org 